\title{
Ask Live! UK public libraries and virtual collaboration
}

\section{Linda Berube}

\begin{abstract}
Author
Linda Berube is Regional Manager for Co-East, the East of England public library networking consortium. She oversees the development and implementation Co-East's interoperability programme and regional ICT strategy and framework. She manages its joint procurement programme.
\end{abstract}

linda.berube@cambridgeshire.gov.uk

\begin{abstract}
Ask A Librarian, the UK public library digital reference service, has been piloting LSSI's Virtual Reference Toolkit. The pilot, managed by Ask administrator Co-East, went live to public users in May 2003 and will continue through September 2003. The pilot objectives include not only an evaluation of the software and support offered by LSSI, but also the eventual integration of the chat component with the main web-form service, and the implications for uptake and sustainability. This article combines a report of the largely positive initial findings of the pilot with an overview of digital reference service and UK public libraries.
\end{abstract}

\section{Introduction}

In 1997, UK public libraries set up their digital reference desk for business. Ask A Librarian (http://www.ask-a-librarian.org.uk) (see Fig.1), arguably the oldest digital reference service, delivered nationally by public libraries, was staffed by the brave, rare few who had access to e-mail and the web in their libraries (and at that time, there were a significant number who did not). Not only were they able to answer any question which came across the desk from anywhere in the world, no mean feat when there were relatively few models or justification for the service in the UK, but also to win accolades from web reviews, as well as the 1999 Virtual Reference Desk Exemplary Service Award (http://www.vrd.org/AskA/Exemplary.shtml)

Now five years on, a lot older and wiser, UK public libraries, through the Ask service, are taking on yet another challenge: integrating the popular web-form service with a collaborative virtual reference service providing live service online (http://www.aska-librarian.org.uk/Patron) . Ask A Librarian, hosted and managed by Co-East (http://www.co-east.net), has been piloting LSSI's Virtual Reference Toolkit (http://www.vrtoolkit.net/) from Jan 2003 until September 2003). This article reports on the pilot and its preliminary findings, as well as reviewing collaborative and integrated virtual information delivery service in public libraries.

The terminology for delivery of information services online can sometimes be confusing. For the purposes of this paper, I have made the following distinction:

- Virtual reference or information service: Real-time reference on the web, using chat, voice, or video; 
- Digital reference or information service: Any reference over the web, including e-mail, web form, or virtual;

- Remote services: includes all the above, and telephone reference.

\section{Collaborative Digital Reference: Public Libraries Lead the Way}

UK public libraries have a long history of collaboration, particularly in the area of print resource-sharing. With the establishment of EARL, the national public library networking consortium in 1996, public libraries moved into the uncharted territory of collaboratively creating and managing web-based services. (Woodhouse, 1998)

At the time, the collaborative delivery of these services made eminent operational sense: for the most part public libraries individually provided little in the way of web access, both for staff and public. In order to learn more about and exploit this new vehicle for service, it was necessary to aggregate what web resource there was and to spread the service across a number of libraries. It also made economic sense; for little investment, libraries without web access had websites, were able to provide web access to their local history and journal collections, and were able to provide a point of access for those who were looking for information online. (Woodhouse, 1998)

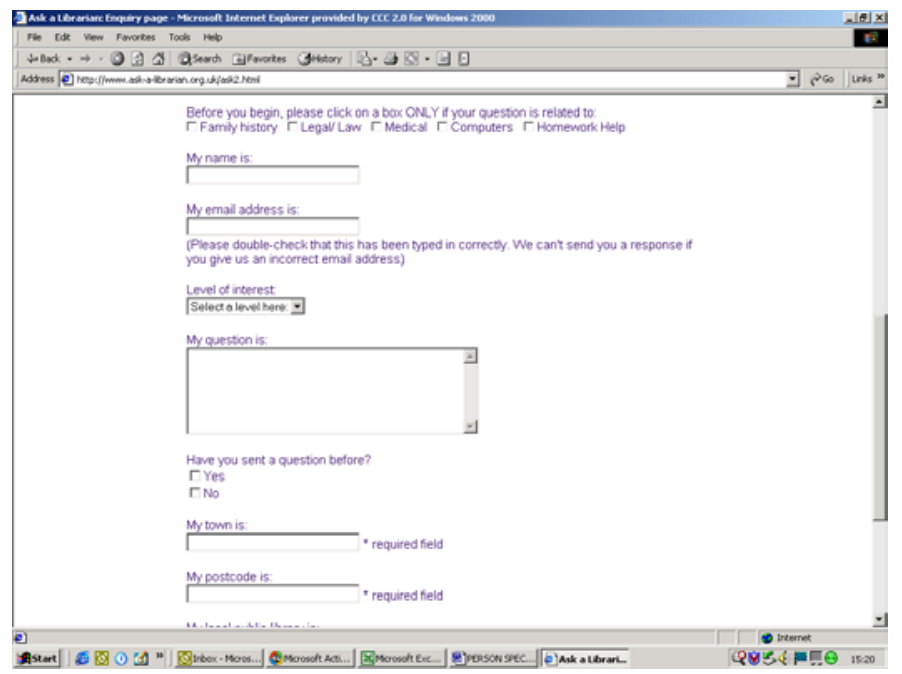

Fig. 1 Ask A Librarian web form screenshot

It is interesting that in these almost post-People's Network days, pretty much the same impetus for collaboration remains. In fact, the motivation supporting collaborative delivery of e-mail based reference pertains to that of virtual reference:

- Cost of local delivery vs initial uptake;

- Collegial support and sharing of expertise;

- Provision of new service and transformation and/or scaling of traditional service;

- Opportunity to deliver on public library and local government agenda, most recently the Framework for the Future (DCMS, 2003)

Collaboration also provides the opportunity for testing an integrated service delivery model. (see Fig. 2 for Keystone Library Network model) Some of the reluctance to negotiate with new virtual technology is down to the "fear factor": fear that the new 
service will drive out the traditional; that web skills will not be able to match user demands and expectations or that staff will be either overwhelmed or underwhelmed with enquiries, both scenarios undermining fledgling service provision.

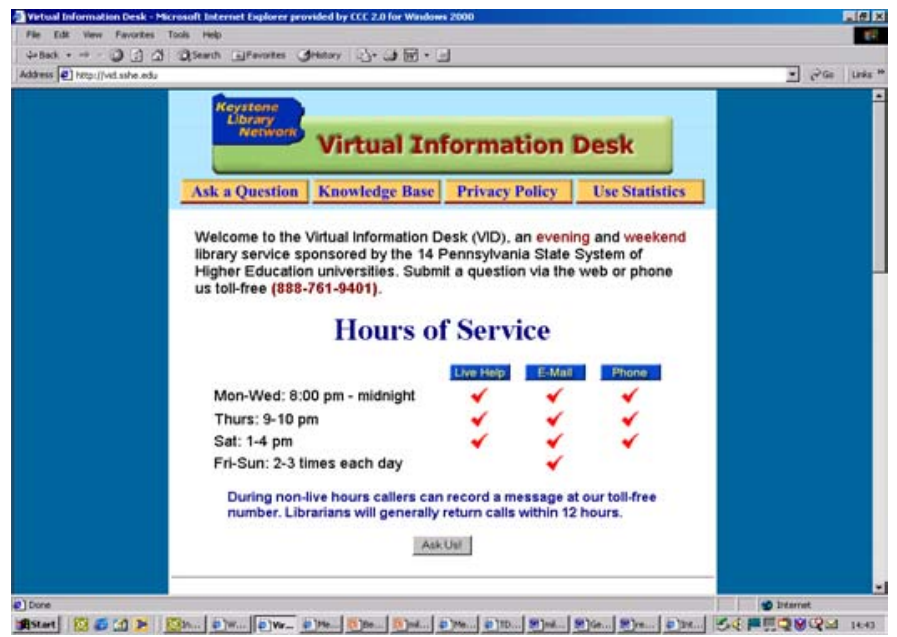

Fig. 2 Example of collaborative integrated service

Co-East and the Ask Live! Pilot Team are looking at how the web form and virtual service can be practically integrated so as to add value to the national and local services. Moreover, we have encouraged public librarians to evaluate how virtual reference will integrate with traditional reference services, for instance telephone reference, at the local level. Statistics from the US suggest that telephone enquiry is still the most popular form of service, but that chat is steadily growing and outstripping email transactions: for example, between August and December 2992, New York Public Library's Remote Reference reported a total of 20,492 questions, $81 \%$ phone; $14 \%$ chat; $5 \%$ email. (Brady, 2002) There seems to be an obvious impact on existing services, but not necessarily in an immediate, exponential way. A comparison study with UK telephone information services would be interesting as telecommunications infrastructure is costed differently than in the US. Another difference between telephone reference in the two countries is the use of call centres by local authorities in the UK.

The potential for similar information service delivery growth in the UK must be considered. However, librarians must ultimately be led by their users, especially at the local level. There is no denying the "chicken and egg" syndrome in introducing and implementing new service: the more librarians learn about their users, the better they are able to provide leadership and guidance in information exchange. The national collaborative service can provide a model and framework from which local services can be customised.

\section{Information exchange in the digital environment}

As demand for remote services grows, the staff and management perspective of them must change. These types of services cannot be regarded as 'extra' or as services that can be delivered only when there is enough staff and time. By gaining experience in, 
and setting up, these multi-level services now, librarians are preparing themselves for the inevitable shift to communicating with users online.

It is not by accident that I have focused on librarians' experience and reaction to the new technology and service. Evaluation and response to users in the digital reference transaction is a relatively recent focus, (Gross, 2001) but given increasingly higher profile with such projects as McClure and Lankes' Assessing Quality in Digital Reference. (McClure and Lankes, 2001)

This "user-based reference" recalls librarians to traditional reference principles, as applied to the digital and especially virtual environment:

- Users get what they want even when they don't know what they want (a significant outcome of the successful reference interview);

- Users get assistance at point- and time-of-need;

- Users get help wherever they happen to be;

- Technical and policy barriers-to-entry must be very low;Users get the very best information, regardless of the format or ownership;

- Print, CD and other traditional formats must be made web-shareable;

- Users will think of the service as a Web resource;

- Users will see it as a part of the fabric of the library. (Brady, 2002)

It is a regular occurrence in Ask A Librarian transactions for librarians to conduct protracted reference interviews via email. However, email does not naturally lend itself to this type of interaction. Virtual reference provides an environment in which librarians and users can communicate directly. Gone is the anonymity and distance of email as librarians rediscover the importance of building a rapport with users, as they lead them through the information search.

Ask Live：A Virtual Reference Trial (Ask A Librarian, 2003) (see Fig. 3)

\section{Background}

Co-East and the Ask A Librarian Advisory Group began discussing a pilot of LSSI's Virtual Reference Toolkit in Spring 2002. During the exploratory phase we prepared a brief for the librarians to take back to their managers, detailing the benefits that experience with the service would provide:

- It increases the points of access to resources and professional guidance for users;

- It allows a broader range of users more opportunities to communicate with us (addressing social inclusion);

- The specific software has potential e-government, distance learning, and remote training application (there is specific application for call centres as well as library information services);

- It raises the profile of public librarians as information professionals;

- It is an excellent training tool for web and customer service skills (i.e., NOF Advanced Training Outcomes);

- It puts people-librarians and users-at the heart of the information transaction. 
As a result of this briefing, an Ask Live! pilot team was assembled, including the following public library authorities: Birmingham; Bradford; Cambridgeshire; Essex; Leeds; Lewisham; Luton; Norfolk; North Yorkshire; Plymouth; Tameside; Wiltshire.

The pilot was initially scheduled to take place between Jan and May, but has since been extended to the end of September 2003. Launching of the service was gradual and in steps: the pilot team peer-trained, then cascaded training or demonstrated to other staff members; librarians from around the country were invited to trial in April; the service was opened up to general users in May. So that librarians could gain confidence and not be overwhelmed (the 'fear factor') we confined the scheduling to hour time slots on Tuesdays and Thursdays. As confidence was built, librarians took on longer timeslots. Also, we are planning to experiment with different hours over the summer; librarians are currently being scheduled for evenings and Saturdays, as well as Tuesdays and Thursdays during the day.

The objectives of the pilot included the following:

- Trial of a new type of service and software;

- Staff and user evaluation;

- Exploring a new service delivery model with the current Ask service;

- Exploring sustainability of the new service.

In addition to achieving the original objectives, there has been two significant outcomes:

- The librarians were not simply trialling software; the pilot itself has enhanced the skill and knowledge base of those involved;

- Depending upon how active each library was in promotion at the local level, the pilot raised the visibility of the library in the local authority. 


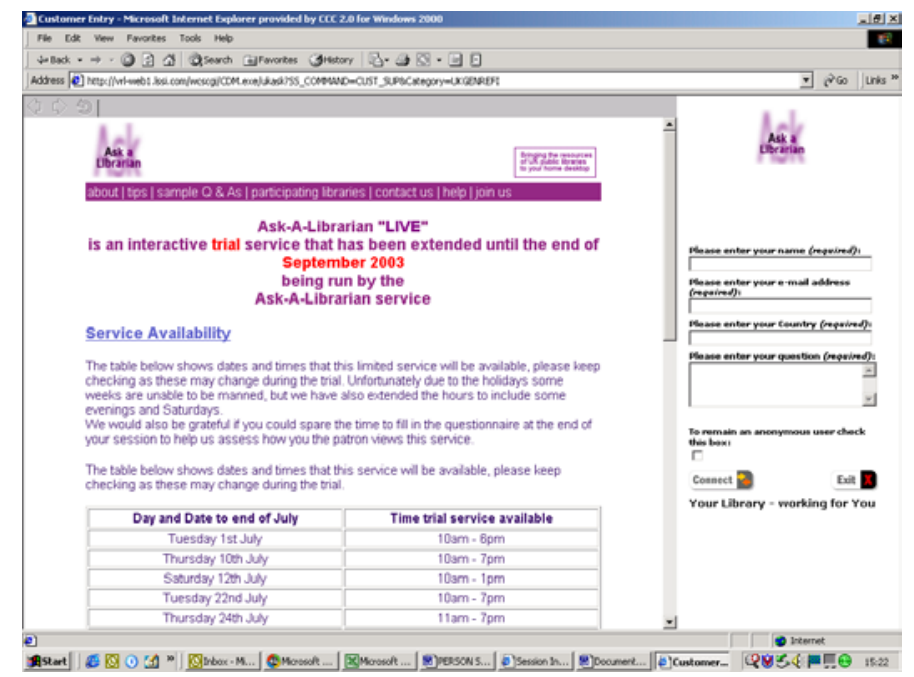

Fig. 3 Ask Live! User Interface

\section{Software}

In deciding to go with LSSI's Virtual Reference Toolkit, three factors were crucial:

- Supplier experience with large collaboratives;

- Supplier support for training and problems;

- Range of functionality.

This last factor was perhaps the most important of all. We evaluated other software packages and services, and although cost was an important issue, we approached the pilot from the perspective of experimenting with functionality: the LSSI Virtual Reference Toolkit offered the highest level of functionality allowing us not only to experiment with application in library information services, but also in other local authority services: pilot team librarians demonstrated the Toolkit to e-government officers; call centre managers; as well as training and distance learning managers. Of particular interest was the ability to share and co-browse (escorting users/staff through web searches) web and non-web materials (commercial electronic databases; powerpoint presentations; word and pdf files etc).

In addition, LSSI has provided a potential model for delivering digital information service to ethnic communities. The Spanish Digital Reference Toolkit (LSSI, 2003) does not simply provide an interface in Spanish; Spanish-speaking librarians from around the country (currently, US) staff the service. So, if a library has a Spanishspeaking user-base, but unable to provide an adequate local Spanish digital reference service, it is able to buy into this service for its users. This collaborative digital information service for ethnic communities would certainly be a model worth exploring in the UK: for example, the Co-East public library partnership has identified an urgent requirement for linguistic expertise to aid in building collections and web content and services for the region's ethnic communities. A test bed model could involve mapping Gujurati-speaking library staff around the country (there is also potential for involving international partners as well) for participation in a national service that would add value to local public library services. 
Also, LSSI Reference Division's recent acquisition by Tutor.com (Tutor 2003) provides an opportunity for integrating online homework clubs with digital information services.

\section{Pilot components}

Various steps in the process of setting up and running the pilot included the following:

- Configuration and setting up user accounts;

- Creating user-interface web page;

- Working with corporate IT partners (to ensure compliance, compatibility etc);

- Remote and on-site training;

- Peer to peer training;

- Trial with users;

- Data collection, including qualitative feedback from exit questionnaire and transaction transcripts. (see Fig. 4)

Arranging training was a particular challenge, especially finding a venue that was central enough as the pilot libraries were so widely spread. In the end, Ask Live! training was hosted by New College Library in Birmingham where staff were also learning to use the ToolKit. In addition, we arranged for remote training with an LSSI trainer for Wiltshire and Plymouth.

Another complication in the start-up stage involved dealing with different authorities' corporate IT partners. The problems occurring with at least two IT departments were not just a function of the specific software, but were indicative of a lack of understanding about the way libraries do business, especially web business and the priority library services were accorded in the authority IT environment.

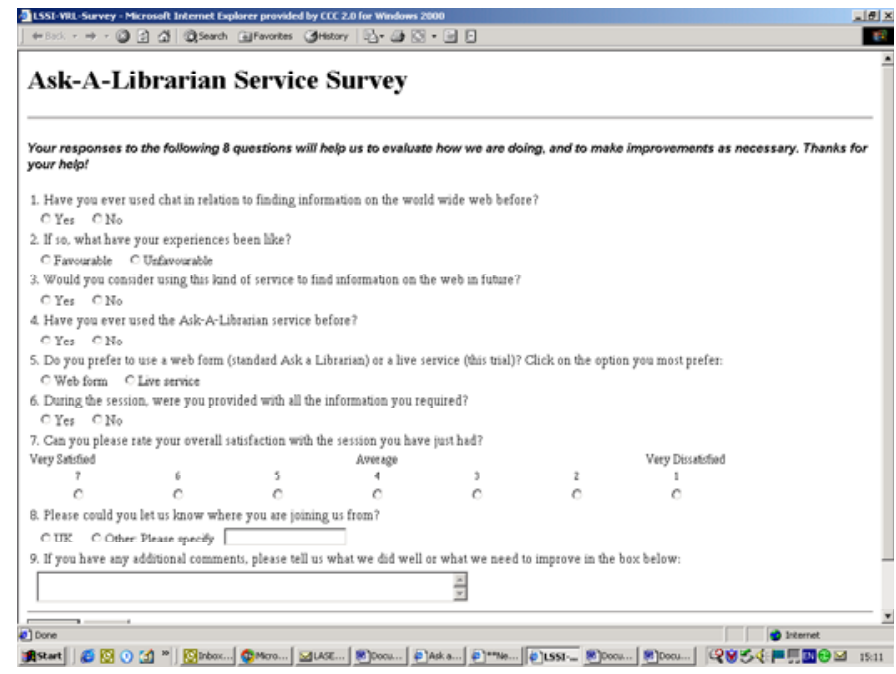

Fig. 4 Ask Live! Exit questionnaire

\section{Preliminary Findings: User Feedback}

As the roll-out to users has been relatively recent (15 days as of the beginning of June), the findings reported here can only be considered preliminary. Librarians have completed 78 transactions; of the 78 (non-librarian) users, 10 filled out the exit questionnaire. The number of transactions is not inconsequential considering the 
limited service days, the choice of either chat or web-form service, and little to no publicity at the local authority level. However, we are planning more promotion for summer and autumn, with flyers and email distribution within the public library authorities.

Ordinarily, this little data would not allow for definitive conclusions; however, what we have seen thus far certainly reflects findings from other more well-established projects and services, for example those reported by the Open University Library's Librarian On Call. (Payne and Perrot, 2003)

The feedback from the exit questionnaire included the following:

- Of the 78 calls, 75 from UK, 2 were from Iran, (1 from North Poland from Santa Claus!);

- $60 \%$ had not used any form of chat prior to this;

- $70 \%$ found it a favourable experience;

- $90 \%$ would consider using this kind of service to find information on the web in future;

- $60 \%$ had previously used the standard Ask-A-Librarian service;

- $60 \%$ preferred the live service to the web form;

- $100 \%$ were provided with all the information they required.

The following comments come from the questionnaires, as well as from the transcripts of the transactions, valuable qualitative evaluation tools in themselves:

- Excellent service. this being the first time I've used 'live' it was a bit strange seeing the answer to my question appear before me on screen, but great idea and will certainly use in future.

- That's brilliant - Thanks - great service, hope it continues after the trial period.

- It's a good service - one small question does the website meet accessibility criteria for people using access technologies?

- Response time was fairly slow.

There are a number of issues raised that we would examine more closely before committing to the specific software or this type of service. For instance, accessibility would have to be addressed; this is not specific to LSSI, but to most products currently available. There is the option for add-ons to improve accessibility, but these can sometimes be deterrents to use. We are currently discussing with LSSI possible enhancements to the software.

A recurrent problem, noted not just by users but by librarians as well, is the interruption of service and delayed transmission. The Open University recorded a comment from one user: "... it would be easier to call up the dead". (Payne and Perrot, 2003) We can match this with one from our own pilot: "It was like watching grass grow!" Again, technical problems are common with this type of software, essentially middleware that can be locally or remotely hosted (while both types of hosting is an option with the ToolKit, we are accessing the service remotely during the pilot). While it is true that the more sophisticated the functionality the more likely the problems, less sophisticated software packages are no proof against them. 
Generally, those reporting problems with the technology fell within the $40 \%$ of average and below levels of satisfaction. Interestingly, of those $40 \%$, all indicated they had received the required information. This finding is significant, and suggests that the vagaries of the technical environment and more importantly the librarian's (in)ability to operate effectively in that environment leave a lasting impression on the user. If a librarian has control over the transaction and environment and is able to assure the user that despite impediments the information will be found and relayed, the user will have confidence in the service.

Another interesting finding concerned the users' willingness to wait if the information was not readily available. In some instances, usually because of technical problems, the librarians would have to send information to users through email. This finding is consistent with that of the Open University service:

...while students were appreciative of an immediate answer delivered via Librarians On Call, they did not require an immediate answer to value the service. Students seemed to want immediate contact with the librarian and a quick response of some type, even when the librarian had to conduct further research and send the final answer to the student via email. (Payne and Perrot, 2003)

This finding would also call into question the 24/7 model, especially for general users. Relatively few of the questions received via the Ask A Librarian web form service require immediate response (Ask guarantees a 48-hour response time, and in a majority of cases responses are sent well within 12 hours). Users are generally grateful for any response, especially free of charge, and this is born out from Ask A Librarian web form transactions.

\section{Librarian feedback}

There was quite a range of feedback from the librarians participating in the project, largely related to trying to launch a collaborative (albeit small) service in gradual stages:

- The initial training was good, and it has been a good opportunity to play with the latest technology. We would not however be interested in using chat at a local level, certainly at the moment.

- Not worried by the lack of demand at this stage, as it is new and there has been no publicity. Also suspect Joe Public does not understand the service yet either.

- If we are able to get proper backing and funding, we could go for some highprofile publicity (in other places other than libraries - radical, I know!) and do the job properly.

- Highlighted the need for a national list of websites, along the lines of BUBL. Even if we don't go down the virtual reference route.

- Remote training although very good couldn't cover everything. More time required to feel confident and hone skills prior to live trial.

- Different reactions/experiences to training and practicing based on local initiative, level of local cascading, and length of trial.

- We'd be glad to take part in the Ask service 'Live' if funding can be arranged.

Regarding uptake and promotion, the visibility of the product within the authority has been dependant on local initiative. Despite promotional activity, other services have 
reported a slow uptake of virtual reference, and as previously noted statistics from the US illustrate that traditional services have yet to be supplanted. To some extent, the "fear" felt by librarians often extends to users: on their first try some users would "hang up", expressing surprise that someone actually responded or that "it really worked". And, of course, the telephone is still the quicker, more widely available and inclusive technology. As pointed out by one of our librarians, although she could see the value of the service and would certainly wish to continue on a collaborative basis, it would be difficult to justify the expense on the local level based on uptake. This is generally the reasoning offered by libraries participating in other collaborative services.

\section{Ask Live! The Future}

As pointed out in the Librarian Feedback section above, future funding for the entire service remains an issue. The service has been supported by a residual grant from EARL prior to its ceasing operation, and most recently from Resource. Co-East and the Ask Advisory are currently exploring options for sustainability, which will include supporting an integrated web form/virtual reference service.

The librarians are unanimous in the benefits of the pilot and the desire to continue with the service. In addition, other Ask libraries have expressed an interest in participating. This interest was very much in evidence at a Co-East sponsored event in early June, Bridging the Divide, attended by over 40 libraries, Resource, NHS librarians, and LSSI, to report on the preliminary findings and the future of the service. The popularity of the Ask service, the increased access offered by the virtual reference component, and the international recognition of one of the original collaborative services combine to provide an excellent model of the value to users, librarians, and public library authorities that collaborative information service can offer.

\section{References}

Ask A Librarian: Ask Live! (2003) Web page. URL: http://www.ask-alibrarian/Patron.

Berube, L. (2003) Digital Reference Overview. URL: http://www.ukoln.ac.uk/public/nsptg/virtual/

Brady, A. (2002) User-Centered Virtual Reference (Source: Harriet Shalat, Supervising Librarian, Telephone Reference Service, Director, Ask Librarians Online), the IFLA Section on Reference Work, IFLA Glasgow.

Department of Media, Culture and Sport (2003) Framework for the Future: Libraries, Learning and Information in the Next Decade. URL:

See also http://www.resource.gov.uk/action/framework/framework.asp. 
Gross, M. et al. (2001) Assessing Quality in Digital Reference Services: Overview of Key Literature on Digital Reference. URL:

Keystone Library Network (2003) Virtual Information Desk. URL:

http://vid.sshe.edu

LSSI (2003) Servicios de referencia en espanol. URL:

http://www.vrtoolkit.net/infofiesta.htm

McClure, C. and Lankes, R. (2001) Assessing Quality in Digital Reference Services: A Research Prospectus.

URL:

Ormes, S. (1998) Public Librarians Corner: Ask A Librarian. URL:

http://www.ariadne.ac.uk/issue13/public-libraries/

Payne, G. and Perrot, M. (2003), Librarians On Call: an instant messaging enquiry service for Open University distance learners 27(85), 11-21.

Tutor.com. (2003) URL: http://www.tutor.com.

Woodhouse, S. (1998) Delivering the New Public Library: the role of the EARL Consortium, INFOCUS 3(1). URL:

http://www.lboro.ac.uk/departments/ls/cti/EARL.html\#intro

$\underline{\text { WORD COUNT } 3,795}$ 